\title{
К вопросу возрождения национальной печати Страны Басков в конце XX в.
}

\author{
Елена Занина
}

В статье исследуется вопрос возрождения и становления национальной печати Страны Басков в конце XX в. Во время правления Франсиско Франко (1939-1975 гг.) баскский язык официально был запрещен. После смерти каудильо в регионе появилась двуязычная журналистика на испанском и на баскском языках. Когда окончательно сформировалась норма баскского языка, началось активное развитие национальной печати на родном языке, что способствовало его распространению.

Ключевые слова: национальная печать, баскский язык, эускара, эускади, двуязычная журналистика.
@ Занина Елена Николаевна кандидат филологических наук, консультант исполнительного директора фонда «Русский мир» (г. Москва, Россия), zanina_elena@mail.ru

\section{Введение}

Испания представляет собой яркий пример полиэтнического государства, которое состоит из семнадцати так называемых исторических областей, четыре из которых являются национальными: Каталония, Галисия, Канарские острова и Страна Басков. Баски являются одним из крупнейших разделенных народов современной Западной Европы, проживающих в двух государствах Европейского союза - Испании и Франции. Разделена Баскония была в $\mathrm{XV}$ в., но все равно осталась пространством одного народа, одного языка. К баскским землям относятся находящиеся в Испании провинции Алава, Бискайа, Гипускоа, составляющие так называемое автономное сообщество Страна Басков, автономная область Наварра, а также три небольшие провинции во Франции, входящие в департамент Атлантические Пиренеи: Лабур, Нижняя Наварра и Суль.

В Эускади (в пер. с баскского - место проживания басков) сформировалась особая этнокультурная идентичность - эускалдунак (житель Эускади). Баски имеют все атрибуты самостоятельного этноса: собственный изолированный язык (эускара), свою культуру и историю. Режим Франсиско Франко (1939-1975 гг.) на несколько десятилетий затормозил национальное развитие региона: 
было запрещено вывешивать национальный флаг, отмечать баскские праздники, давать детям баскские имена. Под запрет попал и баскский язык, «особыми декретами Министерства юстиции от 1938-1941 гг. недвусмысленно заявлялось об особой роли испанского языка, прочие языки в качестве размывающих национальное сознание испанцев подлежали искоренению. Было запрещено издавать книги, газеты и журналы, вести преподавание на баскском языке. Но после падения нацистской Германии в 1945 г. политика Франко под влиянием западных держав, в первую очередь США и Великобритании, стала более либеральной. Начиная с 50-х гг. XX столетия в Испании уже не существовало прямого языкового преследования, не было явного запрета на частное использование национальными меньшинствами своих языков, репрессии постепенно ослаблялись» (Басманова, Миссауи-Ульянищева, 2018: 367).

После смерти каудильо в 1975 г. в Испании начался процесс возрождения малых народов и народностей, обретение ими забытой (или запрещавшейся) культуры, началось активное использование и распространение родных языков, «появились первые газеты и журналы, которые были ориентированы на подъем национального сознания» (Прутцков, 2019: 147). «Информационные структуры, оставшиеся от франкистской эпохи, начинают расшатываться, жесткая конкуренция начинает определять условия функционирования журналистики. Переход от диктатуры к демократии становится временем постоянных преобразований, исчезает самая крупная государственная журналистская сеть - печать франкистского движения» (Garsía, Martínez, 1992: 74).

В 1979 г. был принят специальный закон, устанавливавший статус автономии Страны Басков. Впервые в истории Испании на юридическом уровне баскский народ был признан как отдельный: «Баскский народ, или Euskal-Herria, как сложившаяся национальность для достижения самоуправления образует региональное автономное объединение в рамках испанского государства под названием Euckadi, или Страна Басков»2. В том же году три баскские провинции Бискайя, Гипускоа и Алава были объединены под баскским автономным правительством, а баскский язык на этой территории стал вторым официальным наряду с испанским. Он стал использоваться для публикации правительственных документов, его знание стало необходимым для занятия некоторых должностей, в регионе стала возрождаться национальная печать на родном языке.

Наварра сегодня представляет собственную автономную область, и баскский язык тоже имеет официальный статус на ее территории, а во французской Стране Басков эускара официального статуса не имеет.

Переход от авторитаризма к демократии, который начался в Испании после смерти Франко в 1975 г., вызвал ликвидацию государственной системы прессы и последующую приватизацию газет и журналов. На фоне этих глобальных перемен в журналистике Басконии появилось большое количество изданий двуязычного формата: параллельно печатались информационные материалы на испанском и баскском языках.

Опыт сосуществования такой журналистики в Стране Басков весьма интересен и полезен при анализе истории, развития и современного состояния прессы как стран СНГ, так и стран Европы, где малые языки, возрождаясь, начинают играть все более активную роль в жизни этих стран. Проведенные ранее исследования ${ }^{3}$ были ориентированы на анализ изменений в экономической деятельности баскской журналистики в условиях переходного периода (1975-1982 гг.), но «на данном этапе происходили глубокие перемены в информационной политике и внутренней 
структуре средств массовой информации автономного сообщества» (Хенкин, Самсонкина, 2011: 43).

Развитие национальной печати Страны Басков было непосредственно связано с формированием единого нормированного баскского языка. В начале демократических реформ в регионе произошел колоссальный рост печати на эускара. Но «в борьбе за профессионализм и собственный стиль в национальной печати журналисты натолкнулись на трудности, вызванные отсутствием единой литературной нормы баскского языка и недостаточным опытом его применения в журналистике» (Мартинес де Лесеа, 2011: 54). Одним из факторов, ускоривших образование единого языка, стала национальная печать, точнее «пропаганда баскскими журналистами идеи национального возрождения, выразившейся, прежде всего, в борьбе за формирование литературного и нормированного баскского языка» (Lecours, 2007: 57). «Враждебная политика федеральных властей Испании по отношению к этому региону на протяжении почти всей его истории оказалась для национального языка очень вредоносной, поскольку в силу исторических обстоятельств он не имел столь прочной базы в обществе, как, например, каталонский, и не был в такой степени разработан, систематизирован и унифицирован» (Saiz, 1977: 67).

\section{Из истории баскского языка}

Баскский язык имеет довольно сложную истории. «Это единственный реликтовый язык в юго-западной Европе, сохранившийся с доримских времен. Немецкий филолог Хуго Шухардт (1842-1927) выстроил гипотезу о том, что баскский язык имел генетическую связь с ныне исчезнувшим иберийским, и что оба эти языка имеют семитохамитскую основу» (Torrealday, 1977: 17).

Советские лингвисты А. Манделеев и А. Кикнадзе выдвинули гипотезу о родст- венности баскского и кавказских языков, предположив, что прародина басков находилась на территории современной Грузии, которую они покинули 3,5 тысяч лет назад 4 . В современных генеалогических классификациях баскский язык фигурирует как язык «вне группы» (Ландабасо, Коновалов, 2004: 34). Баскологи (Доджсон, 1896; Марр, 1933-1937) различают две основные группы диалектов: западную, или бискайскую (с центром в Бильбао), центрально-восточную, включающую французскую, лабурдинскую (с центром в Байонне), нижне-наваррскую (с центром в Сен-анПье-де-Пюр) и сулетинскую (с центром в Мопеоне). Языковеды (Гереньо, 1983; Летамендиа, 2016; Могель, 2013) насчитывают восемь основных диалектов баскского языка и двадцать пять второстепенных, причем эти диалекты довольно далеки друг от друга (даже само название баскского языка различно в различных диалектах).

Несмотря на репрессии со стороны режима Франко Академия баскского языка продолжала свою работу по унификации эускара. «В 1964 г. на французской территории, в Байонне, собрались баскские филологи, литераторы и журналисты Испании и Франции для того, чтобы создать модель единого языка. С 1968 г. под эгидой все той же Академии начали действовать рабочие комиссии, специально созданные для реализации достигнутых в Байонне соглашений. Проблемы орфографии, морфологии, склонений, спряжений и прочего были в основном решены. Наконец в 1973 г. новый стандарт языка, названный euskara batua (объединенный баскский) был принят в окончательной редакции. В итоге в основу современного стандартизированного баскского языка - так называемого эускара батуа (euskara batua) - были положены центральные диалекты (наваррский, гипускоанский и лабурдинский) с использованием некоторых особенностей периферийных диалектов» (Diaz, 1994: 253). 
На сегодняшний день эускара батуа является ведущим вариантом баскского языка, на котором, наряду с государственным испанским, осуществляются коммуникации, включая газеты, радио и Интернет.

«К началу 80-х годов XX в. автономное правительство Страны Басков субсидировало довольно густую сеть учреждений, приобщавших к баскскому языку местное население. В регионе активно началась лингвистическая "эускаризация". Этот процесс активно идет и сегодня, это подтверждается растущей с каждым годом популярностью как самого языка, так и газет и журналов, печатающихся на баскском языке» (García, Martínez, 1992: 45).

Лингвистическая унификация языка изначально проходила в борьбе с консерваторами и приверженцами местных, традиционных языковых форм, но, в конце концов, была успешно завершена. Носители языка в значительной части не умели правильно читать и писать на нем, испытывали в той или иной мере комплекс неполноценности в связи с тем, что изучение эускары не считалось престижным. «Было развернуто движение по созданию школ с преподаванием на баскском языке - так называемых икастол (ikastolak), помимо икастол для детей возникли так называемые эускальтеги (euskaltegui) - центры обучения баскскому языку взрослых. В 1968 г. в Испании еще правила диктатура Франко, поэтому создание таких школ происходило в условиях "незаконности", эти икастолы могли существовать только на частные средства» (Кожановский, 2003: 109).

После падения диктатуры Франко процесс изучения баскского языка пошел интенсивнее, и поддержка автономного правительства Страны Басков этому способствовала: начались институализация икастол, придание им официального статуса и укрепление их материальной базы, на ряде факультетов университетов в расписание был включен один час в день на изучение баск- ского языка. «Существование и дальнейшее развитие баскского языка самым непосредственным образом было связано с формированием баскской народности как самостоятельной этнической общности, что, в свою очередь, во многом было обусловлено теми историческими процессами, которые происходили в данном регионе (Alvarez, 1996: 78).

\section{Появление двуязычной периодики}

Первый взлет журналистики на баскском языке, точнее на разных его диалектах, был в период Второй Испанской республики (1931-1939 гг.). Новая Конституция, принятая 9 декабря 1931 г., «признавала за регионами право на широкую автономию, гарантировала гражданам равенство независимо от происхождения, пола, социального положения, политических убеждений и религиозных верований, отделение церкви от государства, свободу совести и религиозных верований, неприкосновенность жилища, тайну почтовой переписки, свободный выбор профессии, свободу торговли и промышленности, свободу печати и отмену цензуры, свободу собраний и союзов» 5 .

Лидер двуязычной журналистики Страны Басков в тот период издание El Correo Español - El Pueblo Vasco. Это ежедневная газета, издаваемая в Бильбао. «Под названием El Pueblo Vasco, газета была основана в 1910 г. братьями Фернандо, Габриэлем и Эмилио Ибарра де ла Ревилья. Изначально придерживалась консервативных, клерикальных, монархистских и автономистских позиций, из-за которых в 1936 г. была закрыта республиканским правительством. В 1937 г., после захвата Бильбао сторонниками Франко, газета возобновила издание в сотрудничестве с El Correo Español - печатным органом Фаланги (испанской фашистской партии). В 1976 г. El Correo Español El Pueblo Vasco стала самой продаваемой газетой на севере страны, опередив тради- 
ционного конкурента - La Gaceta del Norte (газета просуществовала с 1901 по 1987 г.) (García, Martínez, 1992: 78). Издательство располагало и располагает достаточно обширной сетью корреспондентов, пользующихся эксклюзивными услугами таких информационных агентств, как Fax Press и Colpisa, что позволяло широко освещать на своих страницах и национальные, и международные события. El Correo Español El Pueblo Vasco печатало на баскском языке в основном материалы рекламного характера, а информационные сообщения попрежнему писались на испанском.

В этот период другая известная баскская газета El Diario Vasco (начала выходить с 27 ноября 1934 г.) стала «шире размещать на своих страницах материалы на баскском языке: это были уже настоящие статьи на культурную и религиозную тему» (Torrealday, 1977: 551). Следом за El Diario Vasco наваррская газета Diario de Navarra (дата основания - 3 января 1901 г.) «стала выпускать раз в две недели отдельную страницу под названием Nafar iskuntan orría, где печатались внештатные журналисты только на баскском языке» (Diaz, 1994: 173).

Таким образом, в регионе начинает активно развиваться так называемая двуязычная периодика: газеты или журналы печатают на своих страницах часть материалов на испанском языке, а часть на баскском.

В эпоху Франко, когда баскский язык был официально запрещен, журналисты изредка пишут небольшие заметки на баскском языке. Так, в 1966 г. газета La Voz de España (выходила с 1936 по 1980 г.) «придумала рубрику Basarri, в которой печатались небольшие материалы на темы, связанные с баскской культурой и сельской жизнью местного населения. Позже в рамках этой газеты выпускалась еженедельная страница под названием Igandeco Euskal orría, где наряду с другими материалами печатались уроки баскского языка по методу Йона Оньябеитиа» (García, Martinez, 1992: 34).
К концу правления Франко «в Стране Басков 90\% - это журналистика на испанском языке и только 10\% на баскском» (García, Martínez, 1992: 56). После падения режима национальный язык в Басконии начинают использовать достаточно активно и как язык общения местного населения, и в средствах массовой информации.

«В 1977 г. в регионе начали издавать газеты Deia (существует до сих пор) и Egin (была закрыта в 1998 г.). Это были издания националистической направленности, поэтому подача, объем и языковые акценты в них сместились: впервые самые важные информационные материалы печатались на баскском языке, а второстепенные на испанском» (Alvarez,1996: 152). Изначально журналисты опасались, что материалы на баскском языке будут непонятны местному населению, и начали с того, что писали на эускара только аннотации сообщений, сам текст по-прежнему печатался на испанском языке. Однако со временем ситуация изменилась, и уже целые информационные материалы можно было прочитать на баскском языке.

Одно из старейших изданий региона Diario de Navarra (выходит с 1903 г.) в 90-х годах XX в. тоже начинает публиковать местные новости на баскском языке. Сегодня это одно из самых популярных изданий среди жителей Наварры - его читают почти 83\% населения провинции (Caminos, Sose, 1994: 25).

23 октября 1989 г. в Стране Басков стартовал проект El Mundo País Vasco. Газета выходит во всех трех баскских провинциях. «Концепт этого издания заключается в том, что помимо новостей Страны Басков в свои выпуски издание включает несколько страниц мадридской газеты El Mundo del Siglo Veintiuno, поскольку мадридская редакция финансирует часть проекта» (García, Martinez, 1992: 84).

Газета Diario de Noticias (выходит с 1993 г.) яркая, полноцветная, привлекающая моло- 
дых читателей Страны Басков - тоже начала активно использовать баскский язык на своих страницах. Основные темы издания связаны с экологией, здоровьем, спортом и отдыхом.

В 1976 г. на собрании баскских журналистов обсуждался Декрет о двуязычной журналистике в регионе. В ходе этой дискуссии был сделан вывод о том, что развитие двуязычной печати наносит ущерб журналистике на баскском языке, и необходимо полностью переходить на родной язык. Однако общий уровень знания баскского языка как среди населения, так и среди самих журналистов был достаточно невысок. Так, например, в 1976 г., когда в Испании начался переход к демократии, в Стране Басков работало около 200 журналистов, при этом только семь из них хорошо понимали и писали по-баскски (Aramburu, 2016: 78).

\section{Национальная печать на баскском языке}

После падения диктатуры Франко в 1975 г. в Стране Басков началась активная популяризация баскского языка, и журналистика региона всячески этому способствовала. Издаваемые на эускара журналы Argia (основан в 1919 г.) и Anaitasuna (выходит с 1924 г.) объявили 1976 г. годом баскского языка в баскской журналистике и «поставили перед собой две основные цели: повысить профессиональный и языковой уровень местных журналистов и сформировать собственный стиль баскской печати» (Caminos, Sose, 1994: 78).

В 1986 г. баскское правительство решило спонсировать проекты еженедельных печатных изданий на баскском языке. Первоначально были представлены три проекта: два предлагали газеты Egin и Deia, третий - журнал Argia. Проект редакции Egin вышел в свет 26 сентября 1986 г. под названием Hemen, а 5 октября того же года был опубликован проект Deia, который назывался Eguna. Газеты были полностью напечатаны на баскском языке и, благодаря правительственной поддержке, издавались четыре года. Но местные власти не устраивала их так называемая национальная активность: газеты не выходили по выходным дням и мало писали именно о событиях Басконии. В 1990 г. они прекратили свое существование.

После их закрытия журналисты Agria aктивно начали разработку нового проекта на баскском языке. Была создана специальная ассоциация журналистов, которая разрабатывала новую модель национального печатного издания на баскском языке. В результате в 1990 г. появился журналистский печатный проект - Egunkaria. «Предполагаемый тираж издания был 700000 экз. Тираж рассчитывался с учетом тех басков, которые хорошо владели родным языком. Egunkaria стала печатным органом баскской ультранационалистической партии Batasuna. Но как только в 2003 г. Верховным судом Испании партия была закрыта, газета сразу же прекратила свое существование» (Сорвина, 2016: 47).

Параллельно власти Басконии поручают известному журналисту Хосе Рамону Белоки возглавить рабочую группу по подготовке еще одного издания на баскском языке. И 6 декабря 1990 г. выходит газета Euskaldunon Egunkaria с тиражом в один миллион экземпляров с распространением во всех семи баскских провинциях (четыре испанских и три французских). Отметим, что такого масштаба в истории национальной печати Страны Басков еще не было (Caminos, Sose, 1994: 68). Но и это издание постигла участь Egunkaria: с прекращением деятельности партии Batasuna газета перестала выходить в свет. Таким образом, судьбу этих газет определили излишняя политизированность и зависимость от политической партии.

На протяжении всей своей истории баски стремились подчеркнуть свою самобыт- 
Таблица. Национальная печать Страны Басков в начале XXI века представлена следующими изданиями

\begin{tabular}{|c|c|c|c|c|}
\hline Издание & Место издания & Язык & Тираж & Сайт \\
\hline EL Correo & Бильбао & испанский & 130000 & www.elcorreo.com \\
\hline Deia & Бильбао & $\begin{array}{l}\text { испанский } \\
\text { и баскский }\end{array}$ & 15000 & www.deia.eus \\
\hline $\begin{array}{l}\text { El Diario } \\
\text { Vasco }\end{array}$ & Сан-Себастьян & $\begin{array}{l}\text { испанский } \\
\text { и баскский }\end{array}$ & 68000 & www.diariovasco.com \\
\hline $\begin{array}{l}\text { Noticias } \\
\text { Gipuzkoa }\end{array}$ & Сан-Себастьян & $\begin{array}{l}\text { испанский } \\
\text { и баскский }\end{array}$ & 34000 & www.noticiasdegipuzkoa.eus \\
\hline Berria & Андоайн & баскский & 25000 & www.berria.eus \\
\hline Kronika & Эрнани & баскский & 20000 & www.kronika.eus \\
\hline $\begin{array}{l}\text { El Mundo País } \\
\text { Vasco }\end{array}$ & \begin{tabular}{|l|} 
Мадрид \\
и Бильбао \\
\end{tabular} & $\begin{array}{l}\text { испанский } \\
\text { и баскский }\end{array}$ & 72000 & www.elmundo.es/pais-vasco \\
\hline $\begin{array}{l}\text { Diario } \\
\text { de Navarra }\end{array}$ & Наварра & испанский & 49880 & www.diariodenavarra.es/ \\
\hline $\begin{array}{l}\text { Diario } \\
\text { de Noticias }\end{array}$ & Наварра & $\begin{array}{l}\text { испанский } \\
\text { и баскский }\end{array}$ & 17000 & www.diarionoticias.es/ \\
\hline Donostitik & Сан-Себастьян & испанский & 13000 & www.donostitik.com \\
\hline $\begin{array}{l}\text { Gipuzkoa } \\
\text { Gaur }\end{array}$ & Сан-Себастьян & $\begin{array}{l}\text { испанский } \\
\text { и баскский }\end{array}$ & 15000 & www.gipuzkoagaur.com \\
\hline $\begin{array}{l}\text { La Tribuna } \\
\text { del Pais Vasco }\end{array}$ & Сан-Себастьян & испанский & 23.000 & www.latribunadelpaisvasco.com \\
\hline $\begin{array}{l}\text { Conecta } \\
\text { Bidasoa }\end{array}$ & Ирун & $\begin{array}{l}\text { испанский } \\
\text { и баскский }\end{array}$ & 11000 & www.conectabidasoa.com \\
\hline $\begin{array}{l}\text { Diario noticias } \\
\text { de Alava }\end{array}$ & Витория & $\begin{array}{l}\text { испанский } \\
\text { и баскский }\end{array}$ & 15000 & www.noticiasdealava.eus \\
\hline Eldiarionrte.es & Витория & $\begin{array}{l}\text { испанский } \\
\text { и баскский }\end{array}$ & 12000 & www.eldiarionorte.es \\
\hline Gasteiz hoy & Витория & $\begin{array}{l}\text { испанский } \\
\text { и баскский }\end{array}$ & 13000 & www.gasteizhoy.com \\
\hline Norte Expres & Витория & испанский & 18000 & www.nortexpres.com \\
\hline $\begin{array}{l}\text { Euscadi } \\
\text { Noticias }\end{array}$ & Витория & $\begin{array}{l}\text { испанский } \\
\text { и баскский }\end{array}$ & 15000 & www.euskadinoticias.es \\
\hline
\end{tabular}

ность и в первую очередь свой уникаль- пользовать родной язык в своей работе: с ный язык. «К началу XXI в. 32,2\% жителей его формированием шло и развитие наСтраны Басков понимали и общались на циональной печати на эускара. Именно двух языках, 49,6\% общались только на унификация системы баскского языка споиспанском и 18,2\% знали баскский язык, собствовало развитию национальной журно предпочитали говорить на испанском» налистики Страны Басков. В свою очередь, (Lecours, 2007: 87). С конца прошлого сто- активное стремление местных журналистов летия баскские журналисты стали чаще ис- издавать газеты и журналы на баскском 
языке ускорили процесс его окончательного формирования. Этот процесс продолжается уже в новых медиа XXI в. Сегодня почти все медиа региона в своей работе используют баскский язык (см. табл.) ${ }^{6}$.

\section{Заключение}

Глобальные перемены, которые начались в Испании после смерти Франсиско Франко в 1975 г., самым непосредственным образом отразились на развитии Страны Басков. Демократические преобразования вызвали глубокую трансформацию баскской журналистики. Впервые после смерти испанского диктатора в регионе началось активное распространение баскского языка, и возрождение национальной печати этому активно способствовало.

Языковая политика Страны Басков в конце прошлого столетия имела излишнюю идеологическую нагрузку. «Экстраординарная политизация баскского общества отразилась на информационном рынке региона: любое политическое или общественное объединение хотело иметь свой печатный орган» (Мартинес де Леcea, 2011: 65). Национальные информационные проекты на баскском языке стали возникать именно из политической сфе- ры. Газеты именно националистической направленности Egin и Deia стали первыми публиковать информационные журналистские материалы на эускара, а издания Egunkaria и Euskaldunon Egunkaria стали рупором ультранационалистической партии Batasuna, и существовали до тех пор, пока партию не запретили.

В конце XX в. в Стране Басков окончательно завершился процесс лингвистической эускаризации - был утвержден единый нормированный баскский язык. До этого местные журналисты пробовали писать статьи на различных диалектах эускара, пытаясь таким образом найти приемлемые формы использования языка в журналистике, и благодаря формированию национальной печати произошла адаптация недостаточно пластичного баскского языка к гибким формам газетной речи. Огромное желание местной прессы использовать родной язык сталкивалось с низким уровнем его знания не только среди местного населения, но и среди самих журналистов Страны Басков. Потребовалось несколько лет, чтобы баскский язык и в регионе в целом, и в региональной журналистике в частности стал таким же равноправным, как испанский.

\section{Примечания}

${ }^{1}$ K началу 30-х гг. XX в. в среде баскских националистов оформилась программа борьбы за достижение государственной независимости. Основным пропагандистским лозунгом с этого времени становится географическое понятие Эускади (Euskadi) (в пер. с баскского - место проживания басков). Этот термин, впервые предложенный отцом-основателем баскского национального движения Сабино де Араной, означает предполагаемую в будущем суверенную баскскую конфедерацию трех провинций Страны Басков, особой автономной области Наварра и трех районов, ныне находящихся на территории Франции.

2 Ley Orgánica 3/1979, de 18 de diciembre, de Estatuto de Autonomía para el País Vasco. Режим доступа: https://www.boe.es/buscar/pdf/1979/BOE-A-1979-30177consolidado.pdf

3 Основные работы по истории средств массовой информации Страны Басков автором данной статьи изучены и представлены в библиографическом списке. 
4 Большая советская энциклопедия. М.: Сов. энциклопедия, 1980. С. 56.

5 Испания в период Второй Республики. Режим доступа: https://www.promotour. info/spain/history/history43.php (дата обращения: 13.05.2020).

6 Prensa Escrita. Режим доступа: https://www.prensaescrita.com/euskadi.php

\section{Библиография}

Басманова А.А., Миссауи-Ульянищева Е.В. Сепаратизм в Стране Басков // Вестн. РуДН. Сер.: Политология. 2018. № 3. С. 365-375.

Гереньо Ш. Простой метод изучения общего баскского языка. М.: Изд-во Wilsen Editorial, 1983.

Кожановский А. Народы Испании во второй половине XX века, М.: РАН, 2003.

Ландабасо А.А., Коновалов А.М. Терроризм и этнополитические конфликты. Кн. первая. Из истории басков. М.: Огни, 2004.

Марр Н.Я. Избранные работы. М.-Л.: Гос. акад. истории материальной культуры (ГАИМК), Гос. соц.-эконом. изд-во (ГСЭИ), 1933-1937.

Мартинес де Лесеа Т. Легенды Эускалеррии, М.: Герника, 2011.

Прутцков Г.В. Особенности освещения референдума о независимости Каталонии в прессе США и Великобритании // МедиаАльманах. 2019. №1. C. 147-160. DOI: 10.30547/mediaalmanah.1.2019.147160

Сорвина М. Сепаратисты Европы и Азии. От басков до курдов. М.: Вече, 2016.

Хенкин С., Самсонкина Е. Баскский конфликт. Истоки. Характер. Метаморфоз. М.: Изд-во МГИМО, 2011.

Alvarez G.O. y otros (1996) Prensa Nacionalista vasca y emigracion a America. Bilbao: Universidad del Pais Vasco (1900-1936).

Aramburu F. (2016) Patria. Barselona: Tusquets Editors.

Caminos M., Sose M. (1994) Transformacion de la prensa en Guipuzcoa durante la transicion politica: la Voz de Euskadi:nacimiento y fracas de un proyecto informativo. Bilbao: Universidad del Pais Vasco.

Diaz N. J. (1994) Los inicios de la prensa vasca: primeros pasos y formas protoperiodisticas (siglos XVII-XIX). Bilbao: Universidad del Pais Vasco.

Dodgson E.S. (1896) Inscriptions basques : «Neuskarajko Scributoak». Madrid: Establecimiento tipográfico de Fortanet.

García C., Martinez A. (1992). Los medios de comunicacion en el Pais Vasco. Bilbao: Universidad del Pais Vasco.

Lecours A. (2007) Basque Nationalism and the Spanish State.USA: University of Nevada Press.

Letamendia J.A.(2016) Método de aprendizaje individual del euskera. España, País Vasco: Ediciones Elkar.

Mogel J.A. (2013) El doctor Peru Abarca. España, País Vasco: Ediciones Elkar.

Saiz V. A. (1977) Triunfo y tragedia del periodismo vasco. Madrid: Editora nacional.

Torrealday J.M. (1977) Euskal idazleak, gaur. Jakin: Oati. 